\title{
Research on the deficit irrigation scheduling to winter wheat at critical period based on crop modeling method
}

\author{
Wang Ya-xu, 2, a, Sun Hong-quan ${ }^{1,2, ~ b}$, Lv Juan ${ }^{1,2, ~ c}$, Su Zhi-cheng ${ }^{1,2, d}$ \\ ${ }^{1}$ Research Center on Flood and Drought Disaster Reduction, Beijing 100038, China; \\ ${ }^{2}$ China Institute of Water Resources and Hydropower Research, Beijing 100038, China \\ awangyxiwhr@sina.com bsunhq@iwhr.com clujuan@iwhr.com dsuzhc@iwhr.com
}

Keywords: APSIM model; Winter wheat; Deficit irrigation; Critical period

\begin{abstract}
Less water at critical period has significant effect on crop yield. The deficit irrigation scheduling is important especially for the drought-prone area. The crop water production function frequently used for deficit irrigation analysis neither has the disadvantage in mechanism explanation. In this study, we use crop model instead of the crop water production function to study deficit irrigation scheduling issue for winter wheat in Jinan City, in North Plain of China. The crop model we employed is APSIM model. The model was calibrated and validated specifically for winter wheat in Jinan using data in 2000-2013 years. Three typical years were selected to represent the normal, light drought and drought conditions. There are 24 irrigation scheduling schemes obtained by combination of three deficit irrigation quotas, the $150 \mathrm{~mm}, 100 \mathrm{~mm}$ and $50 \mathrm{~mm}$, and different irrigation dates from early April to mid-May. By simulating and comparing the ultimate yield of each irrigation scheduling for winter wheat in Jinan, we strongly suggest that: 1) if the antecedent soil moisture is low, perform irrigation at the beginning of critical period, 2) if it under drought stress, perform irrigation once in early May, and 3) if severe drought hits, perform irrigation twice, and allocating more quota for the second time.
\end{abstract}

\section{Introduction}

Water is one of the most important necessities of photosynthesis for crop growth. While the arid and semiarid areas do not have abundant rainfall all year around normally, even the humid areas have the dry spell with limited precipitation, that usually the water stored in the soil could not meet the demands of crop growth. Actually, it is not necessary to meet the water requirements through all the periods in the crop growth season. There are several critical periods the water-consumption stages for the specific crop, such as the heading and grain filling stages for wheat [1]. It is proved that additional water supplied for the crop at certain critical periods is significant to get high yield comparatively at the end of the growth season [2]. However, the water capacity available for agriculture somehow will always be very limited. In particular, this kind of situation is very often in North China, which is a drought-prone zone with the major crop wheat. The study of the deficit irrigation scheduling to crops at critical periods is helpful for resisting droughts, maintain crop yield, as well as promoting the development of modern agriculture [3].

Deficit irrigation related issues have been widely studied. J. Miguel Costa found that deficit irrigation is an effective way for saving water by studying the growing processes and yields of various crops with non-sufficient irrigation [4]. A. W. Johnson analyzed the reproductive parameters and physiological characteristics of strawberry under non-sufficient irrigation, resulting that moderate drought stress has little effect on flowering, yet severe drought would reduce the number of flowering [5]. Typically, crop water production function was frequently employed for the analysis of crop water demand, water use efficiency, optimal irrigation scheduling, etc. For winter wheat, Xie Jing use models of Jensen, Blank, Minhas and Stewart to analyze the water demand in Baoding, Hebei province, founding out that the most the water demand is from jointing stage to filling stage [6]. However, crop water production functions are a class of mathematical models, which neither reflect the mechanism of the process of crop growth, nor analyze the water demand in the whole growing season day by day [7]. Compared with the generalization process of crop water 
production function, crop model could simulate various physiological parameters during the whole growing season, giving more mechanism explanation.

APSIM (Agricultural Production System Simulator) model which as crop model was originally developed by Australian scientists to simulate the biological process of agricultural systems. It has been widely validated and applied in Australia, New Zealand, the Netherlands, Italy and other countries [8]. Also, a lot of works have analyzed and verified that it is applicable for corn, wheat, soybean and other crops in the North China Plain, Northeast China and the Loess Plateau [9-11].

This paper studied the deficit irrigation problem for winter wheat in North China Plain using APSIM model simulation. Basically, we analyzed the variation of crop yields for different deficit irrigation scheduling at the critical period of winter wheat. At the end of this paper, a reasonable irrigation scheduling was presented.

\section{Method and Data}

Method. The semiarid region of the North China Plain is an important grain production base in China. However, in the area, the average annual rainfall is few and the shortage of water resources is very serious. The city of Jinan, our study area, located in the southeast of the Plain. And the winter wheat is widely cultivated at this hill and plain area. In order to study the irrigation scheduling, the irrigation quota, irrigation times and irrigation date were taken into account. The combination of these three aspects can have many kinds of situations. But in case drought hits the region, the water resources available for agriculture were limited and known, then normally the irrigation should be performed at crop critical period once or twice insufficiently, of which this is the basic assumption for our study. Frist of all, the APSIM model was calibrated and validated as described in further detail below. Then, three typical years, 2009, 2001 and 2010, were selected on behalf of the normal year, light drought and drought year, respectively. In which, the typical years selection were determined according to the precipitation frequency analysis in the whole growing season (October 1 to next June 10) instead of the annual rainfall from 1981 to 2014. Subsequently, the water demand and water supply for winter wheat in Jinan were simulated and analyzed. And then, accordingly, three levels of irrigation quotas were assumed, which $150 \mathrm{~mm}, 100 \mathrm{~mm}$ and 50 $\mathrm{mm}$; the irrigation times were set as once or twice; and the irrigation date was at the critical period that during April $5^{\text {th }}$ to May $10^{\text {th }}$. For one irrigation, we let it be at every 10 days; while for two irrigations, we let it be at each of the first day in April and May. According to simulate the growing process for these various scenarios, the ultimate wheat yields were gained under different irrigation quotas. Consequently, the optimal irrigation scheduling is derived from the comparison.

Data. The meteorological data used to drive APSIM model were claimed from "China Meteorological Data Sharing Network" (http://cdc.nmic.cn/home.do). Yet the daily potential evapotranspiration and solar radiation variables were calculated from the meteorological observation data by FAO Penman-Monteith method [12]. Some essential properties, including soil, crop and cultivating (See in Table 1), were come from field investigation and quantitative measurement. And the most widely planted wheat varieties in the region is "Jinan 15" by visiting investigation method. The annual yield data used to calibrate the model were from Shandong Province Statistical Information Website (http://www.stats-sd.gov.cn/).

Table 1 Essential crop and cultivating properties in Jinan

\begin{tabular}{cccccccc}
\hline $\begin{array}{c}\text { Planting } \\
\text { dates }\end{array}$ & $\begin{array}{c}\text { Plant density } \\
\left(\text { plants } / \mathrm{m}^{2}\right)\end{array}$ & $\begin{array}{c}\text { Sowing } \\
\text { depth } \\
(\mathrm{mm})\end{array}$ & $\begin{array}{c}\text { Spacing } \\
(\mathrm{mm})\end{array}$ & $\begin{array}{c}\text { Fertilization } \\
\text { date }\end{array}$ & $\begin{array}{c}\text { Fertilization } \\
\text { Amount } \\
(\mathrm{kg} / \mathrm{ha})\end{array}$ & $\begin{array}{c}\text { Routine } \\
\text { irrigation date }\end{array}$ & $\begin{array}{c}\text { Routine } \\
\text { irrigation depth } \\
(\mathrm{mm})\end{array}$ \\
\hline Oct 5 & 600 & 30 & 200 & Mar 1 & 150 & Mar.1 \& May 1 & 50 \\
\hline
\end{tabular}

\section{APSIM Model Calibration and Validation}

APSIM model has been widely applied and validated in China, however, it is required to evaluate the performance before using it for any specific region. Thus, we rigorously calibrated the APSIM model parameters for winter wheat in Jinan with a series of data in 2001-2010. Yet the 
similar data in 2011-2013 was used to validate the goodness degree of simulation. The major parameters calibrated was as shown in Table 2.

Table 2 Major parameters calibrated for APSIM model in Jinan

\begin{tabular}{cccc}
\hline $\begin{array}{c}\text { Parameter } \\
\text { Type }\end{array}$ & Variety Parameters & Description & Value \\
\hline & vern_sens & Vernalization coefficient & 3.7 \\
photop_sens & Photoperiod coefficient & 4 \\
Parameter & tt_startgf_to_mat & Accumulated temperature of grouting to mature $\left({ }^{\circ} \mathrm{C}\right)$ & 570 \\
& phyllochron & Each leaf development when required heat $\left({ }^{\circ} \mathrm{C} / \mathrm{leaf}\right.$ & 85 \\
Yield & potential_grain_filling_rate & appearance $)$ & 0.0032 \\
parameters & grains_per_gram_stem & Filling of the number of units per stem Grain (kernels/g.stem) & 27.0 \\
\hline
\end{tabular}

Three indicators were employed to evaluate the good degree of the simulation, which are root-mean-square error (RMSE), determination coefficient $\left(\mathrm{R}^{2}\right)$ and Willmott's consistency index (D) [13]. Where $\mathrm{R}^{2}$ and $\mathrm{D}$ indicators reflect the consistency of the simulated and measured values, and the more the value closed to 1 the better the simulation performed. RMSE reflects the absolute error between simulated and measured values, which is expected as small as possible [14].

$$
R M S E=\sqrt{\frac{\sum_{i=1}^{n}\left(O_{i}-S_{i}\right)^{2}}{N}} \quad \text { (1) } D=1-\frac{\sum\left(S_{i}-O_{i}\right)^{2}}{\sum\left(\left|S_{i}-O\right|+\left|O_{i}-O\right|\right)^{2}}
$$

Where, $S_{i}$ is the simulated, $O_{i}$ is the measured, $O$ is the average of measured, and $n$ is the number of samples.

In the study, the RMSE, $\mathrm{R}^{2}$ and $\mathrm{D}$ indicators are 344.0, 0.46 and 0.82 , respectively, which has a good consistency. While the corresponding errors were $0.9 \%, 8.8 \%, 6.8 \%$ in 2011, 2012 and 2013, respectively, which were outperformed. Thus, APSIM model is applicable for winter wheat simulation in Jinan.

\section{Water Demand and Supply Analysis}

In order to determine how much water amount to irrigate normally, first of all, we need to know how much water the winter wheat requried and how much water the soil could supply versus with time in the crop growing process. However, the water demand of any crop varies with the external factors, such as precipitation, soil properties, etc. Therefore, three typical years, 2009, 2001 and 2010, on behalf of nomal, light drought and drought situations, respectively, were selected to: 1) determine the quotas for the deficit irrigation; 2) inspect the variations of different irrigation quota.

It is proved that the critical period of winter wheat is from heading to grain filling stages. Once enter the critical period, the water demand has a large increase than before. In case drought hits in this period, there will be significant yield reduction at the end of the wheat matured. It is relative easy to determine the critical period of winter wheat in Jinan, which the water demand is large from early April (See the sharp increase in Figure 1) to late May (See the steep drop in Figure 1). To determine the irrigation amount is a systematic and sophisticated work. The basic hypothesis we assume is that the irrigation quota in the experiments is to meet the water demand in normal year, yet partially meet, i.e. the deficit irrigation, in light drought or drought years. By simulating the water demand and supply process with various amounts of irrigations at the beginning of critical period, ultimately we found that $150 \mathrm{~mm}$ irrigation on April $5^{\text {th }}$ could meet the in future water demand in normal year. This situation is demonstrated in Figure 1(a), in which the curve of soil water supply of $150 \mathrm{~mm}$ irrigation in red solid line is above the soil water demand of no irrigation in black dashed line and $150 \mathrm{~mm}$ irrigation in cyan solid line for normal year. However, for the drought hits situations in Figure 1(b) and Figure 1(c), $150 \mathrm{~mm}$ irrigation is unsufficient. Some more requied to explain is that the curves of soil water demands of irrigated (cyan) and unirrigated (black) situtations almost the same is because the water demand is determined by the crop physiological 
process instead of the external conditions. Besides, there are several peaks on the curves of the soil water supply for the both situations (red and pink), this is because there is a rainfall previously which supplement water into the soil. Moreover, the soil water supply (red) before critical period in 2009 is comparatively lower than in 2001 and 2010, which this would affect irrigation scheduling described following.

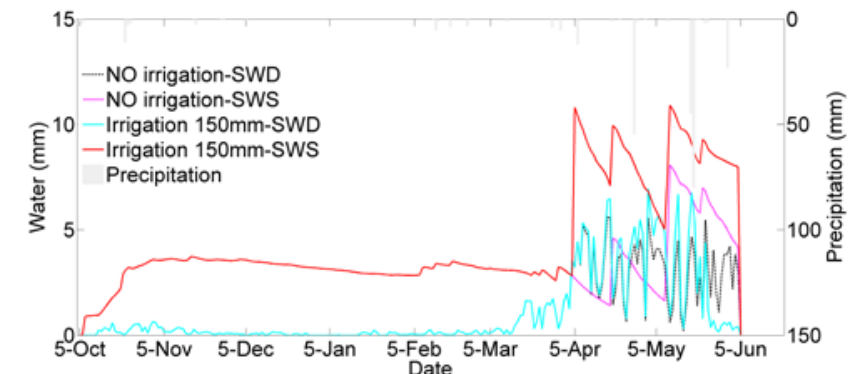

(a) Normal

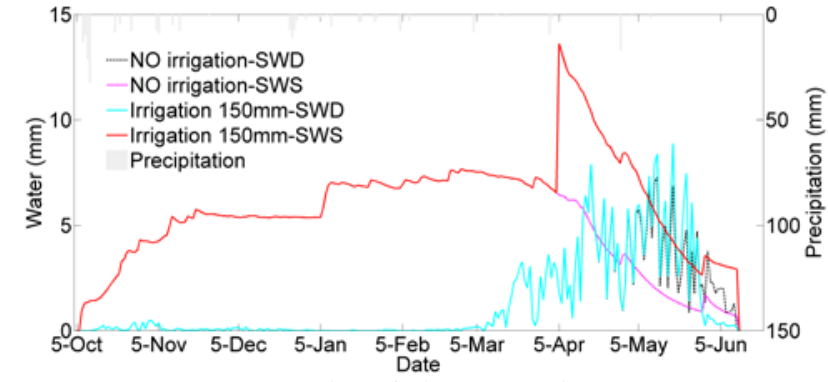

(b) Light Drought

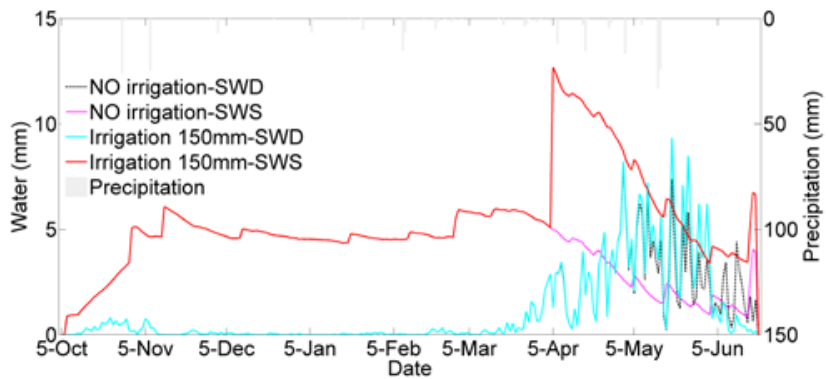

(c) Drought

Note: SWD—soil water demand; SWS—soil water supply

Fig. 1 Dynamic variations of soil water demand and supply for winter wheat during growing season in different typical years, (a) normal year in 2009, (b) light drought year in 2001 and (c) drought year in 2010.

\section{Irrigation Scheduling Evaluation}

We know that $150 \mathrm{~mm}$ irrigation at the beginning of the critical period is generally sufficient for winter wheat in normal year, while insufficient in light drought or drought years. However, in order to inspect the variations of different deficit irrigations explicitly, additional comparison groups, 100 $\mathrm{mm}$ and $50 \mathrm{~mm}$ were put into together. The irrigation date is another issue involved. Since the water demand is little before April and after mid-May, then we only considered the critical period. Consequently, the experiments were designed as described previously, which 24 different deficit irrigation scheduling schemes were performed from April $5^{\text {th }}$ to May $10^{\text {th }}$, which one-time irrigation with 10 days interval and two-time irrigation on April $1^{\text {st }}$ and May $1^{\text {st }}$, respectively (See details in Table 3). Nevertheless, even if many more scenarios considered, we could not exhaust all possibilities. Only by these schemes did we discover the inner patterns.

First of all, we examine the bundles of one-time irrigation. In Figure 2, for any line, each marker in the line represents the yield with respect to the same quota irrigation scheduling at different date. It is evident that the more water irrigated, the larger the yields are (see from the three quotas with different colors). And, generally, the yields trend is comparatively high in normal condition than ones under drought stress for a specific irrigation amount (e.g. see the $150 \mathrm{~mm}$ irrigation with red line for different years). But the ranges of yields with repect to the three quotas are significant different for the three typical years, which the three lines in Figure 2(a) more concentrated than the others. This illustrates that the irrigation amount plays a significent role in drought years, proving that deficit irrigation is helpful for increasing grain yields. Yet, the simulated yields are considerably different with the irrigation dates vary. In 2009, for the normal year, the grain yields decreased with time. As mentioned previously, the soil water supply before critical period is less in 2009. Thus, if the antecedent soil moisture is low, might it be better to irrigate at the beginning of the critical period. In 2001, the antecedent soil moisture is not less yet the critical period is insufficient. While 
in 2009, the antecedent soil moisture is comparatively less and the critical period is fairly deficient. For these two cases, the best irrigation window both happened around early May as the associated yields are maximum.

Secondly, as we have found that the optimal irrigation date is either at the beginning of the critical period or at early May, that we set two-time irrigation were performed on April $5^{\text {th }}$ and May $1^{\text {st }}$. And then, for limited total irrigation quota, a step of $25 \mathrm{~mm}$ amount difference was allocated between the two irrigation dates for each scheduling (see in Table 3) to find when and how much to irrigate is optimal. The maximum yields of each typical year for given quotas (except for $50 \mathrm{~mm}$ ) in one-time irrigation are emphasized in bold font in Table 3. As we can see, the maximum yields more often happen if less irrigation on April $5^{\text {th }}$ yet more irrigation in May $1^{\text {st }}$. This illustrates that early May is the time that terribly serious in the water deficit and significant increased in water demand.

At last, the one-time irrigation and two-times irrigations were put into together to look for which scheduling is most reasonable. The maximum yields in two-times irrigation are appeared in underlined in Table 3. As there is only one scheduling sample for $50 \mathrm{~mm}$ quota in two-times irrigation, the scheuling associated with the maximum yield could not represent the optimization. However, for $100 \mathrm{~mm}$ and $150 \mathrm{~mm}$ quotas, the maximum yields present in two-times irrigation in 2009 (normal year), yet in one-time irrigation on May $1^{\text {st }}$ in 2001 (light drought year). This is because the antecendent soil moisture is low in 2009 that on time irrigation at the beginning of critical period is siginificant helpful for yield increased, while the water deficiency in 2001 was increasingly serious with time. As for the drought year in 2010, the maximum yields shcedulings are different for the two quotas. Either $25 \mathrm{~mm}$ on April $5^{\text {th }} \& 125 \mathrm{~mm}$ on May $1^{\text {st }}$ or $150 \mathrm{~mm}$ on May $1^{\text {st }}$ is optimal for $150 \mathrm{~mm}$ total quota, but $50 \mathrm{~mm}$ on April $5^{\text {th }} \& 50 \mathrm{~mm}$ on May $1^{\text {st }}$ had the maximum yield for $100 \mathrm{~mm}$ total quota. This is because the water deficiency was far insufficient from the normal demand in 2010, that the water efficiency would be different for the two quotas irrigation.

In conclusion, if the antecendent soil moisture is poor low, the optimal deficit irrigation should be at the beginning of the critical period in one-time irrigation; if it is in the case of drought stress, the optimal deficit irrigation should be in early May whatever one-time or two-times irrigations.

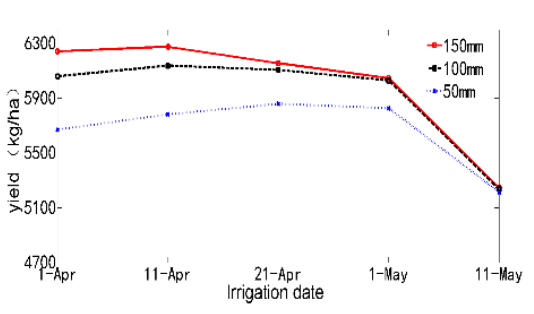

(a)

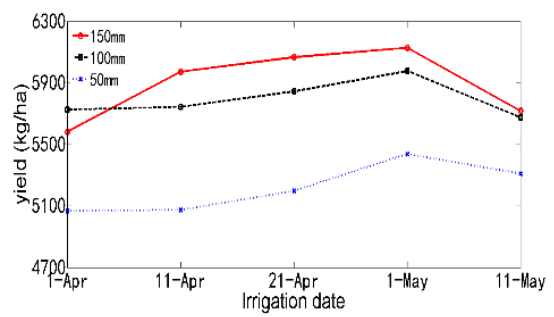

(b)

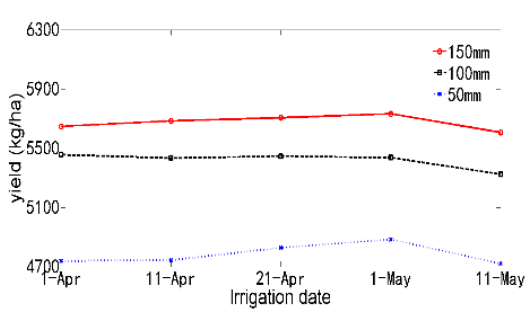

(c)

Fig. 2 The simulated yields with the same quota at a variety of dates for (a) normal year in 2009, (b) light drought year in 2001, and (c) drought year in 2010. 
Table 3 The irrigation scheduling at critical period and the simulated yields of winter wheat in Jinan

\begin{tabular}{|c|c|c|c|c|c|}
\hline \multirow[b]{2}{*}{$\begin{array}{l}\text { Irrigation } \\
\text { Scheduling }\end{array}$} & \multirow{2}{*}{$\begin{array}{c}\text { Total Irrigation } \\
\begin{array}{c}\text { Quota } \\
(\mathrm{mm})\end{array} \\
\end{array}$} & \multirow[b]{2}{*}{ Irrigation Date and Amount } & \multicolumn{3}{|c|}{ Yield } \\
\hline & & & $\begin{array}{c}2009 \\
(\mathrm{~kg} / \mathrm{ha})\end{array}$ & $\begin{array}{c}2001 \\
(\mathrm{~kg} / \mathrm{ha})\end{array}$ & $\begin{array}{c}2010 \\
(\mathrm{~kg} / \mathrm{ha})\end{array}$ \\
\hline 1 & \multirow{10}{*}{150} & $4.5(25 \mathrm{~mm}) \& 5.1(125 \mathrm{~mm})$ & 6242 & 6067 & 5732 \\
\hline 2 & & $4.5(50 \mathrm{~mm}) \& 5.1(100 \mathrm{~mm})$ & $\underline{6286}$ & 6064 & $\overline{5718}$ \\
\hline 3 & & $4.5(75 \mathrm{~mm}) \& 5.1(75 \mathrm{~mm})$ & $\overline{6240}$ & 6065 & 5721 \\
\hline 4 & & $4.5(100 \mathrm{~mm}) \& 5.1(50 \mathrm{~mm})$ & 6240 & 6060 & 5709 \\
\hline 5 & & $4.5(125 \mathrm{~mm}) \& 5.1(25 \mathrm{~mm})$ & 6242 & 5921 & 5699 \\
\hline 6 & & $4.5(150 \mathrm{~mm})$ & 6241 & 5582 & 5647 \\
\hline 7 & & $4.11(150 \mathrm{~mm})$ & 6276 & 5972 & 5684 \\
\hline 8 & & $4.21(150 \mathrm{~mm})$ & 6155 & 6066 & 5705 \\
\hline 9 & & $5.1(150 \mathrm{~mm})$ & 6046 & $\underline{6128}$ & $\underline{5732}$ \\
\hline 10 & & $5.11(150 \mathrm{~mm})$ & 5245 & 5718 & 5606 \\
\hline 11 & \multirow{8}{*}{100} & $4.5(25 \mathrm{~mm}) \& 5.1(75 \mathrm{~mm})$ & $\underline{6216}$ & 5869 & 5454 \\
\hline 12 & & $4.5(50 \mathrm{~mm}) \& 5.1(50 \mathrm{~mm})$ & $\overline{6172}$ & 5798 & $\underline{5465}$ \\
\hline 13 & & $4.5(75 \mathrm{~mm}) \& 5.1(25 \mathrm{~mm})$ & $\underline{6216}$ & 5860 & $\overline{5454}$ \\
\hline 14 & & $4.5(100 \mathrm{~mm})$ & $\overline{6059}$ & 5726 & 5456 \\
\hline 15 & & $4.11(100 \mathrm{~mm})$ & 6137 & 5744 & 5433 \\
\hline 16 & & $4.21(100 \mathrm{~mm})$ & 6106 & 5844 & 5446 \\
\hline 17 & & $5.1(100 \mathrm{~mm})$ & 6029 & $\underline{5977}$ & 5436 \\
\hline 18 & & $5.11(100 \mathrm{~mm})$ & 5233 & 5675 & 5323 \\
\hline 19 & \multirow{6}{*}{50} & $4.5(25 \mathrm{~mm}) \& 5.1(25 \mathrm{~mm})$ & 5738 & $\underline{5798}$ & 4708 \\
\hline 20 & & $4.5(50 \mathrm{~mm})$ & 5669 & $\overline{5069}$ & 4737 \\
\hline 21 & & $4.11(50 \mathrm{~mm})$ & 5781 & 5074 & 4743 \\
\hline 22 & & $4.21(50 \mathrm{~mm})$ & 5857 & 5198 & 4827 \\
\hline 23 & & $5.1(50 \mathrm{~mm})$ & 5826 & 5437 & 4883 \\
\hline 24 & & $5.11(50 \mathrm{~mm})$ & 5212 & 5310 & $\overline{4721}$ \\
\hline
\end{tabular}

\section{Summary}

Although it is hard to get the optimization by water production function method, the crop simulation method could vividly depict the dynamic process of crop growing. This offers us a robust tool to systematically analyze the water demand, water supply and grain yield, etc. By comparing various simulated yields of three quotas at different dates for typical normal, light drought and drought years, we can get some conclusions as follows:

1) The critical period of winter wheat is from early April to mid-May in Jinan. During the period, the water demand is much greater than any other periods. And a few amount of irrigation at critical period will have a significant yield increase, which having high water use efficiency. Such that, if the water resource is limited in drought period. The deficit irrigation is important for improving crop yield.

2) Normally, $150 \mathrm{~mm}$ irrigation would meet the water demand for winter wheat at critical period. If the antecedent soil moisture is low, the suggested irrigation date is at the beginning of the critical period. If the critical period is under light drought stress, the suggested irrigation scheduling is one-time irrigation in early May in Jinan. If the critical period suffered drought, the optimal scheduling is irrigating twice, and allocating more quota for the second time.

\section{Acknowledgement}

This study is funded by the State Natural Sciences Foundation project of China (51209220), Special Fund for Water Resources Research in the Public Interest (201401036), and Fund of China Institute of Water Resources and Hydropower Research (1402, KY1657). The corresponding author 
is Hongquan Sun (sunhq@iwhr.com).

\section{References}

[1] Liu Yanjun, The Effect of Irrigation Rate and Time on Water Consumption and Output of Wheat[J]. Journal of Hebei Agricultural Sciences. 2003,7(2),6-11(in Chinese).

[2] Sun Xianling. Studies Based on Winter Wheat Yield and the evaporation correlation Water-saving Agriculture in Anyang [D]. Southwest University.2012.(in Chinese).

[3] Liu Zengjin, Li Baoping, Li Yuanhua,,ect. Research on the water use efficiency and optimal irrigation schedule of the winter wheat [J]. Transactions of the CSAE. ,2004,20(4):58-63(in Chinese)

[4] J.Miguel Costa,Maria F.Ortuo,M.Manuela Chaves. Deficit Irrigation as a Strategy to Save Water:Physiology and Potential Application to Horticulture[J]. Journal of Integrative Plant Biology,2007,10:1421-1434.

[5] A.W.Johnson,D.W.Simpson. The Effect of Deficit Irrigation on the Flowering Behaviour of Two Day-Neutral and One Everbearing Strawberry Cultivar[A]. International Society for Horticultural Science。International Society for Horticultural Science,2012:4.

[6]. Xie Jing. Study Water Production Function and Water-saving Irrigation System of Winter Wheat in Baoding [D].Agricultural university of Hebei.2011. (in Chinese)

[7]. Hu Baogang, Zhao Xing, ect.Plant Growth Modeling and Visualization - Review and Perspective[J]. Acta Automatica Sinica,2001,27(6),816-835. (in Chinese)

[8]. Shen Yuying, Nan Zhibiao, Bill Bellott,ect. Development of APSIM( Agricultural Production Systems Simulator )and it's application. (in Chinese)

[9]. Caberry PS.Adiku SGK,Mccown RL.et al. Application of the APSIM cropping systems model to intercropping systems. In: Dynamics of Roots and Nitrogen in Croping System of the Semi-Arid Tropics. Japan International Research Center for Agriculture Science.637-644.

[10]. Wang L,Zheng Y-F,Yu Q, Wang E-L,Application of agricultural production and water use of wheat-maize continuous corping system in North China Plain chin J Appl Ecol,2007,18(11):2480-2486.(in Chinese)

[11]. Liu Zhijuan, Yang Xiaoguang, Wang Jing,ect Adaptability of APSIM Maize Model in Northeast China[J]. Acta Agronomica Sinica,2012,38(4):740-746. (in Chinese)

[12]. Classification of meteorological drought (GBT 20481),2006, China Standard Press:Beijing.

[13]. Willmott C J. Some comments on the evaluation of model performance. Bull Am Meteor Soc, 1982, 63: 1309-1313.

[14]. Li Guang, Huang Gaobao. Analysis of cooperation effect of water and fertilizer on wheat and pea in dryland based on APSIM model[J]. Acta Prataculturae sinica,2011,20(5),151-159. (in Chinese) 